\title{
A competição no mercado farmacêutico brasileiro após uma década de medicamentos genéricos: uma análise de rivalidade em um mercado regulado *
}

\author{
Marislei Nishijima ** \\ Geraldo Biasoto Jr. ${ }^{* * *}$ \\ Eleni Lagroteria ${ }^{* * *}$
}

\begin{abstract}
Resumo
O objetivo deste estudo é avaliar a eficácia da regulação da Anvisa sobre as condições de concorrência no segmento de medicamentos éticos do setor farmacêutico negociados em farmácias e drogarias na última década Dois fatos importantes norteiam o período: a regulamentação dos medicamentos genéricos de 1999 e a regulação por controle de preço-teto ocorrida, com mais rigor, a partir de 2003, com a criação da nova Câmara Regulatória de Medicamentos (CMED). Busca-se discutir as principais implicações para a concorrência no segmento, especificamente sobre rivalidade e, em especial, sobre a condição de entrada a partir de informações do setor. A discussão é feita considerando, em paralelo, o ambiente norte-americano de regulação, e seu processo produtivo, que, diferentemente do Brasil, realiza pesquisas e desenvolve medicamentos pioneiros em larga escala. Os resultados apontam para um aumento da concorrência no setor para o caso de medicamentos com patentes expiradas.
\end{abstract}

Palavras-chave: Medicamentos genéricos; Regulação - Condições de entrada; Setor farmacêutico.

\section{Abstract \\ Competition in the Brazilian pharmaceutical market after a decade of generic drugs: an analysis of competition in a regulated market}

The aim of this study is to evaluate the regulatory action by the Brazilian government on the segment of ethical drugs in the private pharmaceutical industry in the last decade. Two important facts guide the period: the generic Drug Law and the regulation of controlling price cap, enforced after 1999, together with the creation of the new Medicines Regulatory Board (CMED) after 2003. The article discusses the main implications of regulation from the point of view of competition, in particular on condition of entry. The discussion considers, in parallel, North American regulatory environment and its production process which, unlike Brazil, do researches and develop pioneer drugs. The analysis points out to the increasing of competition in the sector of drugs with expired patents.

Keywords: Generic drugs; Regulation entry conditions; Pharmaceutical industry. JEL I18, K23, D23.

\footnotetext{
${ }^{*}$ Trabalho recebido em 16 de maio de 2011 e aprovado em 21 de janeiro de 2013.

** Professora Associada da Escola de Artes, Ciências e Humanidades da Universidade de São Paulo (EACH-USP), São Paulo, SP, Brasil. E-mail: marislei@usp.br.

${ }^{* * *}$ Professor Doutor do Instituto de Economia da Universidade Estadual de Campinas. (IE-Unicamp), Campinas, SP, Brasil. E-mail: gbiasoto@uol.com.br.

${ }^{* * * *}$ Mestre pela Faculdade de Economia, Administração e Contabilidade da Universidade de São Paulo (FEA-USP), São Paulo, SP, Brasil. E-mail: eleni@argu.com.br.
} 


\section{Introdução}

Os medicamentos genéricos, após sua regulamentação pelo governo brasileiro em 1999, entraram no mercado a partir do ano 2000. O objetivo dessa política era criar incentivos para a promoção da concorrência no setor. Em 2003, com a criação da câmera de medicamentos, a CMED, o governo brasileiro colocou em curso uma pesada política regulatória sobre o setor com o estabelecimento de preços-teto para os medicamentos éticos, além de uma série de outros controles.

Levando em conta esses acontecimentos e a estrutura produtiva do setor, este estudo busca apresentar as linhas gerais da atuação regulatória do governo brasileiro sobre o segmento de medicamentos éticos, negociados em drogarias e farmácias do setor farmacêutico na última década.

Basicamente dois fatos nortearam o período: a regulamentação dos medicamentos genéricos de 1999, mencionada acima, e a regulação por controle de preço-teto ocorrida, com mais rigor, a partir de 2003, com a criação da nova Câmara Regulatória de Medicamentos (CMED). Além disso, mais recentemente, a regulamentação dos medicamentos similares, em 2007, também teve efeitos sobre o setor.

Busca-se discutir as principais implicações dessas medidas do ponto de vista da concorrência, rivalidade e, em especial, sobre a condição de entrada a partir de informações do setor. A discussão é realizada considerando, em paralelo, o ambiente norte-americano de regulação, e seu processo produtivo, que, diferentemente do Brasil, realiza pesquisas e desenvolvimento de medicamentos pioneiros.

O artigo se estrutura da seguinte maneira, além desta introdução: a seção 1 apresenta brevemente as mudanças regulatórias do setor em suas linhas mais gerais; a seção 2 discute os aspectos produtivos do setor e suas implicações para a concorrência no mercado; a seção 3 apresenta informações sobre o setor e discute a condição de entrada de novas empresas nesse segmento, apontando algumas tendências gerais; e a última seção apresenta as conclusões e considerações finais.

\section{A regulação sobre o segmento de medicamentos éticos no Brasil}

A política de promoção dos medicamentos genéricos após a promulgação da Lei 9.787/99, implantada em 2000, consistiu em criar uma estrutura de incentivos de modo a promover a concorrência no mercado farmacêutico brasileiro. A promoção da concorrência é um instrumento de política que permite aproximar o mercado de dois alvos sociais desejáveis: o máximo bem-estar para o consumidor, que embute a ideia de equidade, e a eficiência econômica (Laffont; Tirole, 1993). 
Com esse instrumento de política, busca-se garantir a disponibilidade de medicamentos substitutos de boa qualidade a preços reduzidos atrelada à redução da assimetria de informação. Isso é realizado por meio de ampla divulgação do controle de qualidade institucional de modo a tornar tais medicamentos substitutos perfeitos daqueles de marca, pioneiros no mercado no tratamento de males e doenças, reduzindo, assim, os custos de tratamentos ${ }^{1}$.

Essa política de incentivo à concorrência foi estabelecida após a adequação do País ao Tratado de Propriedade Intelectual (TRIPS) em 1994, quando grande parte dos países em desenvolvimento passou, na prática, a respeitar o direito de propriedade do setor farmacêutico. Essa estrutura de incentivos, entretanto, operou por curtíssimo período de tempo e de maneira isolada na economia brasileira ${ }^{2}$, pois políticas regulatórias de controle de preços-teto rapidamente voltaram a ser aplicadas concomitantemente, principalmente depois de 2003 com a criação da Câmara de Regulação do Mercado de Medicamentos (CMED).

Em síntese, um arranjo híbrido, conjugando política de incentivo à concorrência com políticas regulatórias restritivas de comportamentos individuais, principalmente na forma de controle de preços, tem caracterizado a atuação regulatória do governo brasileiro sobre o setor farmacêutico nacional na última década ${ }^{3}$.

Outra mudança regulatória importante foi a dos medicamentos similares com a Resolução RDC n. 17, de 03 de março de 2007, que ocasionou, de maneira semelhante ao que aconteceu com os medicamentos genéricos, uma sinalização, por parte do Governo, de controle de qualidade de tais medicamentos. Os medicamentos similares são diferenciados do pioneiro de referência basicamente pela marca e podem variar por forma farmacêutica, por exemplo, entre comprimidos e injeções embora a dosagem e princípios ativos sejam os mesmos. Apresentam o mesmo princípio ativo (mesma molécula) do medicamento de referência, tal como o medicamento genérico, mesma dosagem, mesma posologia e mesma via de administração. Desse modo, por se tratar de um padrão de concorrência na mesma molécula que o medicamento de referência, a concorrência imposta pelo medicamento genérico se assemelha ao medicamento de referência.

O setor farmacêutico brasileiro é regulado ${ }^{4}$ pela Agência Nacional de Vigilância Sanitária (Anvisa), que atua como uma secretaria executiva, conforme

(1) Avaliados pelo valor médio dos medicamentos de referência e genéricos.

(2) Para um estudo sobre o mercado brasileiro no período imediatamente após a implantação da política, ver Nishijima (2003).

(3) A maioria dos países utiliza esse arranjo.

(4) Toda a informação sobre regulação utilizada neste estudo foi obtida no site da Anvisa: www.anvisa.gov.br. 
atribuições previstas na sua lei de criação, a Lei n. 9.782/99, e pelo Ministério da Saúde. Esse ministério, desde 2003, com o Decreto 4.766, passou a ocupar a presidência da nova Câmara de Regulação do Mercado de Medicamentos (CMED), criada em substituição à antiga Câmara Setorial de Medicamentos (Camed), extinta em junho de 2003, cuja presidência era exercida pelo Ministério da Justiça. A substituição da câmara de medicamentos ocorreu com vistas a ampliar seus poderes. Enquanto a Camed só podia responsabilizar os laboratórios, a nova câmara também delibera sobre preços e elabora diretrizes de regulação do setor, podendo responsabilizar todos os agentes do setor farmacêutico: a indústria, o atacado e o varejo.

A Camed, criada pela Medida Provisória n. 2.063/00, posteriormente convertida na Lei n. 10.213/01, tinha caráter provisório e, até 2003, controlava os reajustes de preços dos medicamentos. Nesse caso, o controle se dava por acordos na forma de protocolos de intenção com a Febrafarma (Federação Brasileira das Indústrias Farmacêuticas) e as empresas aderentes com vistas a serem efetivados posteriormente.

A CMED $^{5}$, criada por medida provisória em junho de 2003 e convertida na Lei n. 10.742 do mesmo ano, tem por objetivo, segundo a Anvisa, definir normas claras de regulação econômica para o setor farmacêutico com vistas a promover a assistência farmacêutica à população por meio de mecanismos que estimulem a oferta de medicamentos e a competitividade do setor. Suas atribuições permanentes são: definir diretrizes e procedimentos relativos à regulação econômica do mercado de medicamentos; estabelecer critérios para fixação e ajuste de preços de medicamentos; definir os critérios para a fixação dos preços dos novos produtos e apresentações de medicamentos; decidir pela exclusão ou reinserção de grupos, classes, subclasses de medicamentos e produtos farmacêuticos da incidência de critérios de estabelecimento ou ajuste de preços; e estabelecer critérios para a fixação de margens de comercialização de medicamentos a serem observados pelos representantes, distribuidores, farmácias e drogarias, inclusive das margens de farmácias voltadas especificamente ao atendimento privativo de unidade hospitalar ou de qualquer outra equivalente de assistência médica. O descumprimento das normas deve ser punido com multas.

(5) Trata-se de um órgão interministerial com a seguinte composição de seu comitê técnico executivo de colegiados: secretário de ciência, tecnologia e insumos estratégicos do Ministério da Saúde, que o coordena; secretário-executivo da Casa Civil da Presidência da República; secretário de direito econômico do Ministério da Justiça; secretário de acompanhamento econômico do Ministério da Fazenda; e secretário de desenvolvimento da produção. 
As atribuições da CMED, que regula o comportamento dos agentes laboratórios produtores e importadores de medicamentos, farmácias e drogarias; representantes; distribuidoras de medicamentos; quaisquer pessoas jurídicas de direito público ou privado, inclusive associações de entidades ou pessoas, constituídas de fato ou de direito, ainda que temporariamente, com ou sem personalidade jurídica, que, de alguma maneira, atuem no setor farmacêutico -, como se verifica, constituem políticas bastante restritivas de comportamentos individuais.

No que se refere ao controle de preços, a CMED, em 2003, implantou um procedimento de reajustes de preços anuais, com data-base em março, conforme um modelo de preço-teto seguindo o método Price-cap Regulation 6 . De acordo com essa metodologia, o preço-teto é descrito pela soma de quatro componentes, como mostrado abaixo: variação do índice de preços ao consumidor amplo (IPCA) do IBGE; variação de produtividade (X); e um fator de ajuste de preços relativos entre o setor (Y) e o intrassetor (Z).

De acordo com essa regra de reajuste de preços, os laboratórios produtores podem corrigir os preços dos medicamentos conforme a variação da inflação para o consumidor (IPCA) por aumentos de custos relativos do setor $(\mathrm{Y})$ e por variações relativas de preços dentro do setor $(\mathrm{Z})$. Entretanto, ganhos de produtividade (fator $\mathrm{X}$ ) das empresas, na magnitude de suas projeções, devem ser repassados aos consumidores $^{7}$. O preço-fábrica $(\mathrm{PF})$ corresponde ao preço-teto sugerido aos agentes do mercado e reflete o valor máximo permitido pela agência reguladora. Os preços ao consumidor são monitorados pelo governo como forma de controle por parte da agência reguladora.

A CMED também controla os preços de entrada dos medicamentos no mercado brasileiro conforme regras específicas por tipo de medicamento. Para produtos novos - a serem patenteados no país, mas que representam ganhos para o tratamento na mesma indicação terapêutica em relação aos medicamentos previamente existentes - o preço-fábrica $(\mathrm{PF})$ definido pela empresa não pode ser superior ao menor PF do mesmo produto na Austrália, Canadá, Espanha, EUA, França, Grécia, Itália, Nova Zelândia e Portugal. Caso o produto novo não se enquadre nessa situação, o PF máximo permitido deve ser definido com base no custo de tratamento com medicamento escolhido para comparação.

(6) Essa forma de regulação de preços foi implementada por Stephen Littlechild no Reino Unido - ver Alexander e Irwin (1996) - e apresenta, como característica, o fato de incentivar a produtividade individual das empresas, pois supõe que uma evolução da produtividade do setor acontece a cada período, e, se a empresa não se ajusta a tal evolução, tem seu preço reduzido, mesmo que seu custo não tenha diminuído.

(7) Para o conhecimento da metodologia e cálculo da projeção de produtividade para o setor farmacêutico, ver Rocha e Souza (2007). 
Retomando a discussão sobre o controle de preços de entrada no mercado, uma nova apresentação de medicamento, com a mesma forma farmacêutica e concentração de medicamentos comercializados previamente pela empresa, não pode ter PF superior à média aritmética dos preços dos medicamentos preexistentes. Já para o caso de entrada de uma nova apresentação de medicamento ainda não comercializada pela empresa, ou que seja comercializada com forma farmacêutica diferente, o PF permitido não pode ser maior que o preço médio, ponderado pelo faturamento, das demais apresentações com mesmo princípio ativo $^{8}$, mesma forma farmacêutica e concentração disponíveis no mercado.

Por fim, o PF de um medicamento genérico entrante deve corresponder a $65 \%$ do preço do medicamento de referência em seu lançamento no mercado. A Resolução 2, de 2004, da CMED estabelece que, no ato do registro de um medicamento genérico, seu preço deve ser, pelo menos, $35 \%$ menor do que o preço do medicamento pioneiro de marca ao qual se refere. Desse modo, necessariamente, o custo do tratamento deve cair com a entrada de genéricos no mercado.

No que se refere às compras públicas, considerando que o governo é um grande comprador de medicamentos devido ao programa de "política nacional de medicamentos", a CMED impõe um redutor obrigatório sobre o PF de alguns medicamentos excepcionais ou de alto custo nas compras realizadas pelos entes públicos. Esse redutor, desconto mínimo obrigatório, é o coeficiente de adequação de preço (CAP), que atualmente corresponde a $24,92 \%$.

Os aspectos gerais da regulação descritos acima, tanto em termos de políticas de defesa da concorrência como em termos do controle de comportamentos individuais, podem ser vistos como voltados para a "proteção" do consumidor com o intuito de garantir seu bem-estar. Entretanto, no caso acima citado sobre as políticas de incentivo à concorrência que, por exemplo, buscam eliminar possíveis barreiras à entrada de novas firmas, existe um aspecto de benefício ao produtor potencial entrante à medida que torna mais fácil seu ingresso, ainda que isso ocorra em detrimento do poder de mercado do produtor incumbente. Deve-se observar que, para sanar falhas de mercado e garantir a eficiência econômica, uma política regulatória deve atuar em sentido amplo de modo a garantir condições adequadas para todos os participantes do mercado, genericamente para consumidores e produtores.

(8) Insumo essencial para a produção de medicamentos específicos para cada tipo de doença, também denominado fármaco. Trata-se do componente do medicamento que deve desencadear as reações bioquímicas nos indivíduos com o objetivo de curar um determinado mal. 
Neste último caso, a regulação mais significativa está relacionada com a promulgação da Lei de Propriedade Industrial, Lei 9.279/96, anterior à criação das câmaras de medicamentos - momento em que o Brasil adequou a sua legislação às obrigações do TRIPS (Trade Rights of Intellectual Patents), acordo negociado, em 1994, no âmbito da rodada do Uruguai do GATT (General Agreement on Tariffs and Trade) -, que, na prática, resultou no respeito à lei internacional de patentes $^{9}$ por parte do País.

No Brasil, parte significativa da produção de medicamentos, inclusive no que se refere às multinacionais, consiste na manipulação de princípios ativos importados. Apesar de se verificar, no País, a presença de empresas verticalizadas, as economias de escala envolvidas no processo de pesquisa e desenvolvimento de novos medicamentos das empresas multinacionais pioneiras acabam mantendo tais etapas de descoberta de novas moléculas restritas a seus países de origem. Sendo assim, até então, havia pouco incentivo à adesão das leis de patentes na medida em que poucas empresas potencialmente registrariam novas patentes. Além disso, deve-se observar que a própria concepção do preço de regulação associada a estruturas de monopólio busca definir uma rentabilidade adequada ao setor com vistas a manter as empresas operando no mercado.

\section{Diferenças nos processos produtivos da indústria farmacêutica entre países}

Em geral, o ciclo de vida de um medicamento inovador, pioneiro, apresenta três fases distintas: i) o período de Pesquisa e Desenvolvimento (P\&D) de um novo ingrediente ativo ${ }^{10}$, molécula ou família de moléculas, até a obtenção de patente (se for o caso) e testes pré-clínicos e clínicos para a comprovação de segurança e eficácia do produto com vistas à comercialização autorizada; ii) o período entre o lançamento do novo produto no mercado e a perda de exclusividade dada pela expiração da patente; e iii) período que sucede à expiração de patente, quando o medicamento genérico pode entrar e competir no mercado com o medicamento pioneiro.

Os medicamentos genéricos devem conter os mesmos ingredientes ativos da formulação original, ou seja, os medicamentos de referência. São idênticos ou bioequivalentes ao medicamento de referência com marca no que diz respeito às

(9) Note que, nesse caso, também é possível identificar aspectos benéficos para o consumidor como resultado da política, à medida que o respeito ao direito de propriedade permite que medicamentos novos que curem/amenizem males ainda não tratados possam se tornar disponíveis no mercado, ainda que sob regime de monopólio temporário.

(10) Os testes pré-clínicos e clínicos são aqueles feitos primeiramente em animais; em segundo lugar, em indivíduos sadios; e, em terceiro lugar, em indivíduos enfermos. 
propriedades farmacodinâmicas e farmacocinéticas ${ }^{11}$. Portanto, os genéricos são idênticos na dose, na concentração, na forma de administração, na segurança, na eficácia e na intenção de uso.

Nesse sentido, atendidos os regulamentos e normas que caracterizam os medicamentos como genéricos, estes são tecnicamente considerados substitutos perfeitos dos seus respectivos medicamentos de referência. Portanto, naqueles mercados relevantes ${ }^{12}$ em que se encontram medicamentos de referência com patente expirada, a magnitude das barreiras ao ingresso de novos participantes é determinada pela condição de entrada dos genéricos.

Nos Estados Unidos, que é um país que desenvolve pesquisa e produz medicamentos pioneiros, a lei que rege a manufatura e a comercialização de farmacêuticos no país é o Federal Food, Drug and Cosmetics Act - FFDC. O regulamento requer que qualquer fabricante que deseje lançar um medicamento inovador no mercado demonstre que a nova droga é segura e efetiva para o uso pretendido. O processo de aprovação é demorado e tem custos altos. O fabricante do medicamento deve conduzir testes clínicos e submeter os resultados à análise do Federal Drug and Food Administration (FDA) por meio de requerimento denominado New Drug Application.

Nesse país, assim como em todos os países signatários do TRIPS, após 1997, as patentes para novos medicamentos contam com 20 anos de duração no máximo e 10 anos de duração no mínimo. Entretanto, até 1984, nos EUA, as patentes eram solicitadas e concedidas antes do início dos testes clínicos, portanto, antes do lançamento do remédio no mercado. Desse modo, a vida efetiva da patente de um medicamento acabava por ter duração variável entre sete e doze anos.

Assim, negociações entre o governo norte-americano e empresas interessadas deram origem, em 1984, à alteração da lei de patentes naquele país, possibilitando a extensão do período de vida efetiva de patentes para novas drogas. Como contrapartida, novos incentivos à competição no setor foram introduzidos por meio da simplificação dos procedimentos para o ingresso de medicamentos

(11) Bioequivalência consiste na demonstração de equivalência farmacêutica entre produtos apresentados sob a mesma forma farmacêutica, contendo idêntica composição qualitativa e quantitativa de princípio(s) ativo(s) e que tenham comparável biodisponibilidade quando estudados sob um mesmo desenho experimental; a biodisponibilidade indica a velocidade (farmacocinética) e a extensão de absorção de um princípio ativo (farmacodinâmica) em uma forma de dosagem a partir de sua curva concentração/tempo na circulação sistêmica ou sua excreção na urina (Anvisa).

(12) Mercado Relevante é a definição prática do grupo de substitutos de produtos e de localidades geográficas que compõem um mercado específico de um bem. A sua definição, usada em avaliações antitruste e de regulação em geral, exige técnicas estatísticas específicas. 
genéricos no mercado após a expiração de patentes. Trata-se da "Drug Price Competition \& Patent Term Restoration Act of 1984", conhecida como HatchWaxman Act ou 1984 Act.

Essa lei buscava gerar estímulo e acelerar o ingresso de genéricos no mercado. Para abreviar o lapso de tempo necessário entre a decisão de introduzir um genérico no mercado e a entrada efetiva, permitiu-se, aos fabricantes de genéricos, sob a nova lei, a submissão de um procedimento sumário (Abbreviated New Drug Application - Anda) limitado à demonstração de bioequivalência do genérico em relação ao medicamento de referência.

$\mathrm{Na}$ Europa, onde países como Alemanha, França e Inglaterra são produtores de medicamentos pioneiros, de maneira análoga, os medicamentos genéricos requerem autorizações governamentais para comercialização; mas os requerimentos dispensam a reapresentação de resultados detalhados dos testes clínicos, sendo necessária apenas a comprovação de que o produto genérico é equivalente ao medicamento de referência. A Comunidade Europeia (European Patent Office - EPO) emprega um sistema semelhante ao norte-americano de extensão da vida efetiva da patente. A proteção de uma patente pode durar até 20 anos a partir da data de concessão pelo órgão competente. Para o setor farmacêutico, especificamente, o período de tempo entre o requerimento de patente e o lançamento do produto no mercado pode ser prolongado pelos certificados de proteção suplementar (Supplementary Protection Certificates - SPCS). Esses certificados estendem a proteção efetiva de medicamentos que já estão no mercado por, no máximo, cinco anos ${ }^{13}$.

Para avaliar a lógica das possibilidades de ganhos com o lançamento de um medicamento pioneiro, pode-se verificar as diferenças do fluxo de caixa gerado por um princípio ativo desenvolvido por empresas especializadas em P\&D de fármacos, antes e depois de 1984, nos EUA (Viscusi, 2005). A Figura 1 resume o fluxo de caixa médio gerado por um medicamento inovador nesse país, que pode ser considerado representativo dos países produtores de medicamentos em todas as suas fases produtivas. Entre a origem e o ponto "a", apresentam-se, num período de 12 anos, os custos de P\&D da nova droga e a fase de revisão e aprovação do medicamento pelo FDA. O ponto "a" representa o início do período de comercialização do remédio patenteado, e os lucros oriundos das receitas líquidas são demonstrados pela linha "abcd". No período pós-1984, os lucros passaram a ser descritos pela linha "abefd".

(13) Comissão Europeia. Pharmaceutical sector inquiry - Preliminary report. DG Competition Staff Working Paper, Nov. 2008. 
Figura 1

Fluxo de caixa da atividade inovativa no setor farmacêutico

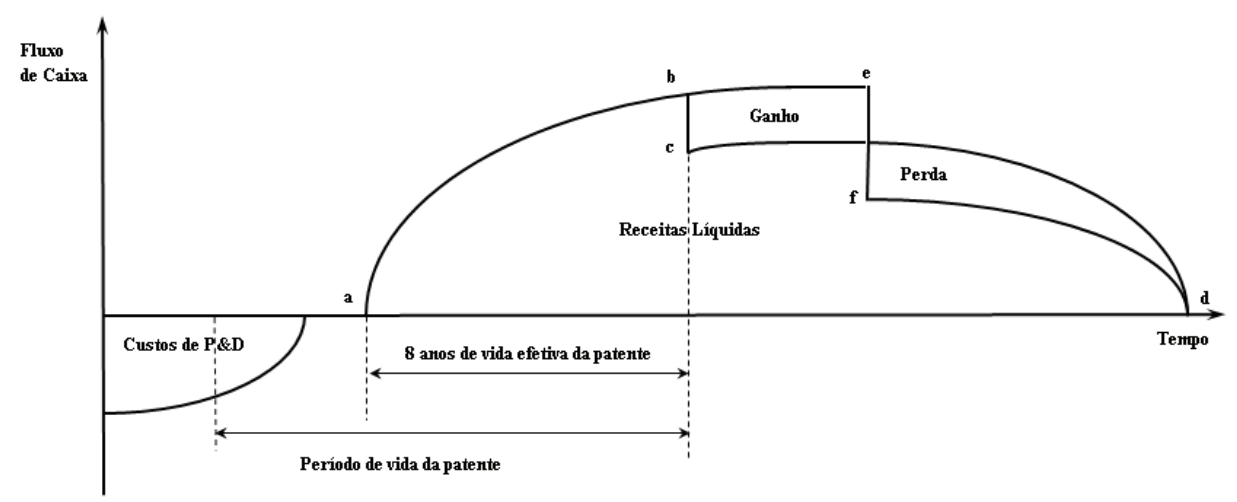

Fonte: Viscusi (2005).

No período pré-1984, a vida legal da patente se iniciava durante a fase de $\mathrm{P} \& \mathrm{D}$ e se estendia por mais oito anos no período de comercialização, como ilustrado na figura acima. A "vida efetiva da patente"14 tinha duração limitada, visto que parte do período de vida legal da patente era consumida na fase précomercialização de $\mathrm{P} \& \mathrm{D}$, testes clínicos, pré-clínicos e cumprimento das demais obrigações regulamentares.

A lei norte-americana de 1984 provê a extensão da vida efetiva da patente igual à soma do período de análise do FDA (em geral dois anos) e a metade do período necessário para testes clínicos, sujeita à dilação máxima de cinco anos e nenhuma ampliação para além de 14 anos de vida efetiva da patente. Na Figura 1, o montante de restauração da patente é representada pela distância "be". Também ilustra a segunda determinação da nova lei norte-americana dada pela distância "ef" de redução brusca das receitas líquidas na data da expiração da patente comparativamente à redução "bc" de receita que ocorria no período pré-1984. As perdas de receita eram relativamente pequenas devido às significativas barreiras à entrada com que se defrontavam os fabricantes de medicamentos genéricos ${ }^{15}$.

Visto que as empresas fabricantes de genéricos frequentemente não podiam se apoiar nas evidências de segurança e eficácia submetidas pelas produtoras de medicamentos de referência, as barreiras à entrada, no período pré-1984, eram significativamente mais restritivas. A menos que dados/informações relevantes fossem disponibilizados ao público pela literatura científica, um fabricante de

(14) "effective patent life".

(15) Portanto, a dimensão relativa das perdas é produto de dois fatores: a probabilidade de entrada dos genéricos e as perdas de receitas ocorridas dada a entrada efetiva de genéricos. Deve-se lembrar que o fluxo de caixa ilustrado na figura se refere ao fluxo médio entre medicamentos e que, no período pré-1984, a entrada de genéricos, em muitos casos, simplesmente não ocorria. 
genérico tinha que duplicar muitos dos testes elaborados pelo inovador para obter a aprovação do FDA.

Como, pela nova lei norte-americana à época, apenas a bioequivalência deveria ser demonstrada, os custos, em tempo e recursos, para a aprovação de medicamento genérico pelo FDA foram reduzidos. Ademais, os testes clínicos das empresas de genéricos no período pré-1984 estavam sujeitos à ação judicial se realizados antes da expiração da patente. Por esse motivo, nos Estados Unidos, a entrada do genérico, quando ocorria, era normalmente observada algum período após a expiração da patente.

A nova lei resultou de um longo período de negociações e compromissos assumidos entre os vários grupos de interesse, envolvendo fabricantes de medicamentos e associações representativas, assim como grupos representantes dos consumidores alinhados com os interesses dos fabricantes de genéricos em favor de preços mais baixos. Como consequência, o Hatch-Waxman Act produziu dois efeitos em sentidos contrários sobre o faturamento dos medicamentos de marca. Enquanto a restauração de patente tende a ampliar a remuneração da empresa que origina o fármaco, a entrada facilitada do medicamento genérico produz uma queda no faturamento mais rapidamente. Dessa forma, as perdas para a empresa pioneira do medicamento correspondem a ganhos para as empresas fabricantes de genéricos. Os ganhos e perdas podem ser visualizados na Figura 1.

Da perspectiva do bem-estar econômico, a lei permitiu ganhos potenciais de dois tipos: primeiro, eliminou a necessidade de testes clínicos de alto custo e sem retorno social (para o lançamento de genéricos), permitindo, assim, uma entrada mais rápida dos genéricos no mercado; segundo, a lei resultou em preços mais baixos para os consumidores e a consequente eliminação do ônus social induzida pela queda do preço de equilíbrio.

De outra parte, o Hatch-Waxman Act tem o potencial de reduzir os retornos esperados pela inovação. Isso depende das magnitudes relativas de ganhos e perdas ilustrados na Figura 1, acima. A avaliação dos resultados da nova lei sobre os incentivos à inovação é, no entanto, uma questão empírica. Além disso, naturalmente, deve-se observar que os efeitos dos incentivos sobre os diversos segmentos são diferenciados nas várias classes terapêuticas

A partir da perspectiva de processo produtivo descrito acima, verifica-se que a Hatch-Waxman Act de 1984 diminuiu as exigências técnicas para reduzir o tempo de entrada dos medicamentos genéricos nos mercados dos medicamentos pioneiros com patentes expiradas nos Estados Unidos, país, este, que é um grande desenvolvedor de medicamentos pioneiros através de elevados gastos com P\&D de novas moléculas ativas. 
No Brasil, por outro lado, tanto a lei de patentes (Lei 9.279 de 14 de maio de 1996), que concede direitos de propriedade ao inventor de fármacos, quanto a lei de genéricos (Lei 9787 de fevereiro de 1999) são bastante recentes relativamente às legislações norte-americanas. $\mathrm{O}$ mesmo fenômeno ocorre nos demais países em desenvolvimento, a exemplo da Índia, que passou a respeitar a lei internacional de patentes pós-TRIPS (Chaudhuri et al., 2006).

Desse modo, no caso brasileiro, a lei de genéricos já foi lançada, em 1999, abrindo mão da obrigatoriedade de testes pré-clínicos e clínicos, exigindo apenas o teste de bioequivalência na ocasião da entrada do medicamento no mercado com o intuito de facilitar o ingresso e a concorrência potencial de tais medicamentos. Apesar dessa simplificação inicial, esse mecanismo operou como um sinalizador de qualidade inédito na atividade produtiva do setor brasileiro, além de criar uma padronização nos produtos substitutos. Antes dessa regulação, com garantias de qualidade atestada pelo governo, a credibilidade dos medicamentos substitutos nos tratamentos ficava praticamente sujeita aos laboratórios produtores (Nishijima, 2003), baseada exclusivamente em mecanismos privados.

A demora para a adequação do Brasil ao TRIPS, embora tenha ocorrido antes da China e da Índia, pode estar relacionada com as características do processo produtivo brasileiro que, predominantemente, não inclui a fase de $\mathrm{P} \& \mathrm{D}$ em quantidade significativa, gerando, dessa forma, baixo grau de incentivo ao engajamento dos produtores domésticos aos direitos de propriedade internacional.

Por parte dos produtores domésticos, ainda que com algumas iniciativas do governo restritas aos laboratórios públicos, tais como Farmanguinhos e FURP, a acumulação tecnológica era muito baixa. Já em relação aos laboratórios multinacionais, assim como aos de outros países em desenvolvimento, a indústria brasileira se constituía num braço da indústria internacional, e a dinâmica espacial de produção e os ganhos de escala envolvidos não direcionavam a atividade de P\&D ao País em quantidade significativa, de modo que ocorria baixo grau de transferência tecnológica por essa via, impedindo, assim, maiores ganhos de disseminação de tecnologia. Além disso, de um modo geral, o País se beneficiava dos "spillovers" das pesquisas e desenvolvimentos realizados pelos países produtores de drogas pioneiras, ainda que isso incorresse no custo de oportunidade de não ter disponível, para consumo imediato, novos medicamentos ou de não ter disponíveis medicamentos para doenças exclusivas do País.

Desse modo, considerando que o direito de propriedade estava justamente atrelado à parte do processo produtivo pouco predominante no Brasil, havia, naturalmente, pouco incentivo imediato para discussões sobre o tema, retardando, assim, o processo de reconhecimento de tais direitos. 
As patentes são vistas com certa tolerância por uma sociedade, apesar da prática de poder de mercado, devido ao estímulo que gera ao progresso tecnológico (Viscusi et al., 2005). No Brasil, essa visão tende a ser pouco clara devido ao fato de o País não incorrer em gastos significativos com pesquisa e desenvolvimento de novos medicamentos e, mesmo assim, encontrá-los disponíveis para consumo (os desenvolvidos por outros países produtores) de modo que a avaliação do retorno econômico dessa atividade é raramente exercitada.

O processo produtivo brasileiro, em sua maior parcela, baseia-se na importação da molécula ativa e composição do medicamento em sua forma comerciável - comprimidos, soluções, xaropes etc. - via manipulação dos excipientes (parte inerte do medicamento) e sua posterior embalagem. De acordo com as informações do Directory of World Chemical Producers (DWCP) ${ }^{16}$, o Brasil importava 80\% dos princípios ativos utilizados em sua produção em 2009.

Os motivos para não se produzir princípios/moléculas ativos ainda precisam ser estudados mais profundamente, mas algumas relações gerais podem ser delineadas. Em primeiro lugar, o Brasil não é historicamente um país pioneiro em pesquisa de novos princípios ativos e de indústria química e bioquímica em geral, fenômeno que garante vantagens aos incumbentes (Grabowski; Vernon, 1992). Em segundo lugar, mesmo para o produtor de princípios ativos com patentes já expiradas, como é o caso da Índia e da China, as economias de escala e o alto grau de desenvolvimento tecnológico no segmento químico de desenvolvimentos de novos princípios ativos tendem a ser proibitivos.

Como o processo produtivo brasileiro realiza relativamente poucos gastos com $\mathrm{P} \& \mathrm{D}$, trata-se de um processo mais curto verticalmente. Assim, tende a ser mais simples e mais barato, principalmente, quando comparado com os custos de desenvolvimento de novas drogas por países que realizam gastos com P\&D e com registros posteriores de patentes das novas famílias de moléculas ativas (princípios ativos) descobertas.

Deve-se, entretanto, qualificar a simplificação analítica adotada acima sobre o processo produtivo farmacêutico brasileiro. Tal simplificação é adequada quando se consideram os laboratórios privados, como empregada na presente análise, embora, ainda assim, existam algumas exceções. No caso dos laboratórios públicos, conforme Magalhães et al. (2011), existe razoável verticalização produtiva, com desenvolvimento de princípios ativos destinados a males pouco rentáveis do ponto de vista privado. Segundo esses autores, os laboratórios oficiais também teriam a função de promover concorrência, pois o anúncio dos laboratórios públicos de que seriam capazes de produzir os princípios ativos de Efavirenz, Nelfinavir e Lopinavir, que são usados na produção de medicamentos

(16) http://www.chemicalinfo.com/dwcp. 
antirretrovirais para o tratamento de pacientes portadores de HIV, teve efeito disciplinador sobre os preços cobrados pelos laboratórios privados. Por fim, importa observar que existem inovações na área de formulações decorrentes do avanço na nanotecnologia e outras técnicas de liberação programada a partir dos antigos princípios ativos e que são sujeitas ao patenteamento, embora a magnitude desses desenvolvimentos, no Brasil, ainda não seja conhecida.

Assim como nos Estados Unidos e Europa, o período de vigência de uma patente no Brasil é de 20 anos. A indústria farmacêutica nacional é basicamente dedicada ao desenvolvimento, produção e comercialização de produtos genéricos e similares a partir de princípios ativos importados e produz medicamentos pioneiros de marca em quantidade muito reduzida. Desse modo, quando uma empresa de um grupo internacional inovador deposita um pedido de patente de medicamento junto ao INPI (Instituto Nacional de Propriedade Intelectual) provavelmente já o fez em seu país de origem e possivelmente em outros países onde haja demanda suficiente para a nova droga ${ }^{17}$.

O Brasil, que possui população numerosa com acesso ainda limitado pela baixa renda a tratamento médico e medicamentoso, dispõe de um grande atrativo para empresas mundiais de farmacêuticos, sobretudo no segmento de genéricos e de medicamentos similares. Além disso, o governo brasileiro é um grande demandante de medicamentos genéricos devido a seus programas e políticas de distribuição de medicamentos à população em geral, que, embora envolvam gastos significativos, ainda não atingem a maior parte da população. Entretanto, não se pode perder de vista que este estudo trata somente dos medicamentos negociados em drogarias e farmácias.

Até a criação da Anvisa em 1999, a autorização para a comercialização de medicamentos era concedida diretamente pelo Ministério da Saúde e fiscalizada por órgãos sanitários estaduais. Ainda que a discussão sobre uma política brasileira para a introdução dos genéricos no mercado fosse antiga, a ausência de regulamentos que protegessem os direitos de propriedade sobre drogas inovadoras impediam o desenvolvimento do mercado de genéricos, uma vez que estes só existem em sua forma regulada quando a sua patente expira, sendo então respeitada como direito de propriedade.

Após a publicação da Lei de Propriedade Intelectual em 1996, os debates sobre a política brasileira de incentivo aos genéricos foram retomados e constaram, expressamente, da Política Nacional de Medicamentos aprovada em outubro de 1998 (Portaria GM 3916/98).

(17) Com efeito, os custos de obtenção de patentes em todos os países onde a droga será lançada são altos e, dependendo da demanda local, as despesas junto ao sistema patentário local podem não compensar o rendimento associado à proteção patentária. 
A lei de genéricos e regulamentos específicos, análogos aos vigentes em outras jurisdições, concede o direito de lançamento de um medicamento genérico após a expiração do direito de propriedade da empresa inovadora sobre o fármaco. A autorização para fabricar e comercializar um produto genérico é concedida pela Anvisa a qualquer fabricante interessado, bastando, para isso, a comprovação de intercambialidade do produto genérico em relação ao produto de referência. Isso reduziu os custos de entrada no mercado de genéricos, facilitando enormemente aqui, assim como nos Estados Unidos e na Europa, o ingresso de medicamentos sem marca ou com mesmo princípio ativo no mercado.

O provimento de incentivos aos fabricantes de genéricos é explícito na Lei 9787/99, que determina que os médicos do sistema único de saúde (SUS) devem receitar medicamentos pelo nome do princípio ativo (sem menção à marca), justamente porque são genéricos, por definição, produtos sem marca. Ademais, as aquisições de medicamentos pela administração pública também deveriam passar a ser feitas com a indicação do princípio ativo, dando-se preferência ao genérico $\left(\right.$ Art. $\left.3^{\circ}\right)$.

Mais recentemente, a Resolução 135/2003 estabeleceu normas quanto à prescrição e dispensação de medicamentos, que claramente promovem o comércio e a concorrência de genéricos no mercado de medicamentos:

1. Prescrição: 1.1. No âmbito do Sistema Único de Saúde (SUS), as prescrições pelo profissional responsável adotarão, obrigatoriamente, a Denominação Comum Brasileira (DCB), ou, na sua falta, a Denominação Comum Internacional (DCI). 1.2. Nos serviços privados de saúde, a prescrição ficará a critério do profissional responsável, podendo ser realizada sob nome genérico ou comercial; 1.3 . No caso de o profissional prescritor decidir pela não-intercambialidade de sua prescrição, a manifestação deverá ser efetuada por item prescrito, de forma clara, legível e inequívoca, devendo ser feita de próprio punho, não sendo permitidas outras formas de impressão. 2. Dispensação: 2.1. Será permitida ao profissional farmacêutico a substituição do medicamento prescrito pelo medicamento genérico correspondente, salvo restrições expressas pelo profissional prescritor. 2.2. Nesses casos, o profissional farmacêutico deverá indicar a substituição realizada na prescrição, apor seu carimbo a seu nome e número de inscrição do Conselho Regional de Farmácia, datar e assinar. 2.3. Nos casos de prescrição com nome genérico, somente será permitida a dispensação do medicamento de referência ou de genéricos correspondentes. 2.4. É dever do profissional farmacêutico explicar, detalhadamente, a dispensação realizada ao paciente ou usuário bem como fornecer toda a orientação necessária ao consumo racional do medicamento genérico. 2.5. A substituição do genérico deverá pautar-se na relação de medicamentos genéricos registrados pela 
Anvisa. 2.6. A relação de medicamentos genéricos deverá ser divulgada pela Anvisa por intermédio dos meios de comunicação.

O objetivo último desse arcabouço legal foi a introdução da concorrência de preço no mercado de medicamentos, onde antes predominava a concorrência em P\&D, e o lançamento de novos produtos, situação propiciada pelo reconhecimento recente dos direitos internacionais de patentes por parte do Brasil. A proteção patentária aos medicamentos inovadores conjugada a outras barreiras legais, como dificuldades de sinalização e controle de qualidade para o lançamento de genéricos, concederia poder de monopólio e margens de lucro altas às empresas farmacêuticas.

\section{Condição de entrada no mercado farmacêutico brasileiro após Lei de Genéricos}

A regulação dos medicamentos genéricos no Brasil, assim como nos Estados Unidos, teve como intuito facilitar a entrada de produtores de medicamentos substitutos no mercado criado pelo medicamento pioneiro, promovendo, dessa forma, a concorrência no setor. Considerando a estrutura produtiva descrita, caracterizando o País como não realizador de gastos com $\mathrm{P} \& \mathrm{D}$, há elementos que sugerem a possibilidade de aumento da probabilidade de entrada de novas empresas produtoras de medicamentos concorrentes aos pioneiros de marca, sejam similares ou genéricos, no sentido de aumentar a concorrência no setor.

Deve-se ainda considerar algumas diferenças entre as barreiras à entrada de genéricos nos Estados Unidos e no Brasil ao final da validade de uma patente do medicamento pioneiro: (i) os laboratórios norte-americanos podem iniciar o desenvolvimento de genéricos apenas após a queda da patente correspondente; no caso brasileiro, no entanto, os laboratórios podem desenvolver o produto e solicitar registro à Anvisa mesmo antes da expiração dos direitos de propriedade sobre o fármaco e lançar o genérico um dia após a queda da patente; e (ii), nos Estados Unidos, o primeiro laboratório a lançar o genérico tem direitos de exclusividade de comercialização da patente por 3 meses, o que não ocorre no Brasil, quando vários laboratórios podem entrar simultaneamente no mercado de um medicamento de referência com patente expirada.

Cabe ressaltar, inicialmente, que as unidades da indústria farmacêutica, no que se refere à produção do medicamento, que já têm o princípio ativo disponível como insumo são, em sua maioria, plantas multiprodutos ${ }^{18}$ e que, portanto, não

(18) Uma exceção poderia ser a produção de alguns medicamentos antirretrovirais que apresentam resíduos não facilmente elimináveis para a produção subsequente de outro medicamento qualquer. 
existem unidades fabris com equipamentos originalmente concebidos para a produção de um único tipo de medicamento. Desse modo, esse processo produtivo não inclui ativos específicos (Milgrom; Roberts, 1996). Considerando que a indústria farmacêutica brasileira não realiza gastos significativos com $P \& D^{19}$, seu processo produtivo, em grande parte, consiste na composição dos medicamentos em sua forma farmacêutica comerciável (comprimidos, pílulas, xaropes etc.) e sua embalagem, fenômeno que é particularmente aplicável aos medicamentos genéricos e similares que se utilizam de princípios ativos/fármacos disponíveis no mercado internacional e que são facilmente importáveis.

Em contraste com os processos contínuos de produção, a indústria farmacêutica opera com processos produtivos em bateladas finitas (lotes) (Matos, 2003), uma vez que o princípio ativo já tenha sido desenvolvido com patente expirada e facilidade de importação e, portanto, disponível como insumo para a produção do medicamento. As linhas de produção farmacêuticas são basicamente dedicadas a quatro categorias de produtos, segundo a forma farmacêutica: sólidos, semissólidos, líquidos e injetáveis. Desse modo, uma grande variedade de medicamentos pode ser manufaturada em um conjunto limitado de tipos de linhas de produção.

Como salientado, a produção farmacêutica brasileira se resume à composição dos medicamentos em sua forma comerciável, ou seja, à mistura de ingredientes ativos e não ativos. Assim, com respeito à tecnologia de produção no País, não são grandes as especificidades ao ingressante potencial, uma vez que entram no mercado com esse mesmo processo produtivo, usando princípio ativo importado, de modo que a tecnologia de produção não é de propriedade das incumbentes. Isso sob a hipótese de grande disponibilidade de importação de princípios ativos de países que produzem em larga escala, como a Índia e a China.

O processo produtivo de cada medicamento é automatizado e detalhado com a correta dosagem de ingredientes a fim de garantir a qualidade dos produtos (Lima et al., 2006). Após a produção de um determinado lote, os equipamentos passam por um processo de eliminação de impurezas, tornando-os aptos a recomeçar o processo e configurar um produto completamente distinto, com outros ingredientes e diferentes passos de processamento.

O processo de produção por bateladas é, portanto, adequado para empresas multiproduto, como os laboratórios farmacêuticos que produzem vários tipos de medicamentos, de tal modo que as linhas de produção podem ser compartilhadas para a manufatura de mais de um produto ou classe de produtos. Como consequência, as empresas envolvidas em negócios com esse perfil podem arbitrar na produção em resposta às condições da demanda de cada um dos seus bens.

(19) Obtém princípios ativos por meio de importações, conforme já discutido anteriormente. 
Sendo assim, em função do sistema de fabricação por bateladas, as linhas de produção da indústria farmacêutica tendem a ser flexíveis e não se destinam à produção de um único medicamento, mas sim a várias formulações que se apresentam sob a mesma forma farmacêutica (Lima et al., 2006).

Decorre também dessa flexibilidade produtiva o fato de que é mais provável que uma nova empresa entrante seja multiproduto para ser competitiva, oferecendo, em contrapartida, maior rivalidade potencial para as incumbentes. Pela lógica do processo produtivo, as empresas entrantes são multiproduto. Outro aspecto dessa flexibilidade da oferta está relacionado com a rivalidade e a concorrência potencial entre as empresas que já operam no mercado. Considerando que todas as empresas que atuam no mercado são multiproduto com flexibilidade de oferta e flexibilidade de composição (mix) de seus produtos, essa possibilidade tende a oferecer maior probabilidade de arbitragem de oferta com implicações sobre preços, principalmente quando o número de produtores é grande.

No que se refere ao custo institucional de lançamento para atender os requisitos legais e regulatórios locais de medicamentos genéricos e similares no mercado farmacêutico para um produtor entrante, a partir de importação do princípio ativo, são mostradas, abaixo, nas Tabelas 1 e 2, em anexo, os custos dos registros de medicamentos genéricos e similares junto à Anvisa, respectivamente. Esses custos se referem às chamadas barreiras institucionais à entrada de novas empresas e são considerados como custos irrecuperáveis (sunk costs) no sentido de consistirem num investimento em ativo específico. Deve-se, no entanto, observar que os governos de vários países, como parte da política regulatória, buscam reduzir tais custos para introduzir competição em preço nos mercados de medicamentos. Conforme discutido na seção 2, enquanto nos Estados Unidos a quebra das exigências de testes clínicos para os medicamentos genéricos foi retirada após a Hatch-Waxman Act, como contrapartida para a ampliação do período de patentes, no Brasil, a lei de genéricos já foi formatada para exigências apenas dos testes de bioequivalência. Assim, no Brasil, esses custos ${ }^{20}$ podem ser resumidos pelo investimento para a obtenção do registro do medicamento genérico ou similar, mostrados nas Tabelas 1 e 2, em anexo.

Os valores mostrados nessas tabelas, em torno de $\mathrm{R} \$ 550$ mil reais de 2009, tanto para o registro de medicamentos genéricos como para similares, devem ser avaliados em relação ao faturamento médio dos produtores por medicamento enquanto for válido o registro. $\mathrm{O}$ registro junto à Anvisa permite ao produtor vender o medicamento genérico ou similar no mercado por cinco anos renováveis a custos menores (em torno de 10\% do valor requerido para o registro inicial e, portanto, em torno de R \$ 50 mil a $\mathrm{R} \$ 55$ mil em valores de 2009).

(20) Obviamente, abstraindo os custos de produção no Brasil, que envolvem custos judiciais, tributários, falta de segurança etc., que supomos afetar todos os setores produtivos de maneira igual. 
A Tabela 3, em anexo, mostra o faturamento corrente, referente ao ano de 2009, de alguns medicamentos pesquisados Essa tabela resume alguns dos resultados de uma pesquisa da Sindusfarma ${ }^{21}$ para o estado de São Paulo. Os valores de faturamento por medicamento para esse ano, que se referem exclusivamente a vendas em drogarias e farmácia ${ }^{22}$, excluindo hospitais e governo, mostraram-se significativamente mais elevados que o custo institucional de entrada dos medicamentos genéricos e similares. Estes últimos são supostos a serem dados pelos custos de registro na Anvisa. A taxa entre o preço do registro e o faturamento no seu período de validade, supondo que o preço praticado não se altere nesse horizonte de tempo, sugere que o custo da regulação é relativamente pequeno no país. Especialmente quando se projeta o faturamento referente ao ano de 2009 por cinco anos, sob a hipótese conservadora de crescimento nulo no faturamento de cada apresentação de medicamento genérico e se verifica o valor do registro relativamente a esse período.

A tabela 4, indica, a partir de informações disponíveis no sítio eletrônico da Anvisa e do IMS ${ }^{23}$ Health, os preços de varejo nas farmácias e drogaria. No que se refere à evolução dos preços como um indicativo de aumento de concorrência no setor, é preciso fazer algumas qualificações preliminares. A primeira é que, sendo o setor farmacêutico de medicamentos éticos regulado por preço-teto pela CMED, tem-se que a lógica de operação de preços no mercado é identificada por descontos. A negociação no mercado entre produtores, intermediários e consumidores ocorre por meio de descontos sobre o preço-teto. Sendo assim, o espaço para a atuação das políticas públicas de defesa da concorrência ocorre sobre o grau de descontos negociados entre setores; o preço-teto, no entanto, é um entrave que impede variações para valores acima desse teto. Note que, em um setor regulado, não pode haver conflito entre a atividade de regulação e a política de defesa da concorrência; se houver, conforme Lisboa (2007), isso se deve ou a problemas de definições de funções, ou à inconsistência temporal.

A segunda qualificação refere-se ao padrão de concorrência entre os medicamentos pioneiros de marca e genéricos. Conforme Grabowski e Vernon (1992), Frank e Salkever (1991), Kamien e Zang (1999), Hurwitz e Caves (1988) e Hellerstein $(1994,1998)$ existem dois tipos de demanda: uma demanda que é leal à marca e outra que percebe o genérico como idêntico ao medicamento de marca e, portanto, é mais sensível às variações de preços. Desse modo, a separação entre

(21) "Pesquisa de Preços de medicamentos Genéricos e de Referência em Farmácias e Drogarias" realizada pela Sindusfarma para 22 medicamentos genéricos. Disponível em: http://www.sindusfarmacomunica.org.br.

(22) Conforme disponibilidade de dados do IMS.

(23) International Medical Statistics (IMS) consiste numa publicação de origem suíça sobre o setor farmacêutico, que apresenta informações mensais tais como faturamento e quantidade de todos os medicamentos vendidos em farmácias e outros pontos de comércio sem incluir hospitais e postos de saúde na maioria dos países em que operam as empresas multinacionais. 
tipos de consumidor implica que quem é leal à marca não é influenciado por variações de preços, ainda que abruptas, dos genéricos. Assim, a concorrência que se estabelece é entre os produtores de genéricos que disputam por consumidores mais elásticos às variações de preços e não sobre o grupo de consumidores fiéis à marca. O benefício social deve ser avaliado, desse modo, pela redução do preço médio do medicamento, e não pela queda de preços de todos os medicamentos envolvidos.

Para verificar a evolução recente dos preços dos medicamentos, utilizamos a tabela 4, em anexo, que mostra os resultados da pesquisa do Sindusfarma no que se refere às variações de preços dos medicamentos genéricos e pioneiros. Verificase que os preços dos medicamentos genéricos em termos percentuais de seu preçoteto são, em geral, relativamente menores que os preços dos medicamentos de referência quando comparados a seus preços-teto, embora a magnitude seja pequena. Essa diferença pode refletir maior competitividade do medicamento genérico vis-à-vis o de marca.

No que diz respeito ao preço relativo do medicamento genérico (que, nesse caso, consiste em uma única apresentação de genérico acompanhado pela pesquisa) sobre o preço da apresentação de medicamento de referência, verifica-se que, geralmente, a diferença de preço é maior que os $35 \%$ estipulados no momento da entrada do genérico no mercado, sugerindo, assim, um padrão mais competitivo para os genéricos.

Numa amostra de 88 classes terapêuticas nível $4^{24}$ disponíveis para esta pesquisa, em 63 delas $(71,5 \%)$ existem medicamentos éticos genéricos, e sua participação no faturamento tem aumentado em cada uma dessas classes, conforme a tabela 5, em anexo, quando se analisa o período de 2002 a 2009. Considerando que os medicamentos genéricos têm preços menores que seus medicamentos de referência, o aumento da participação no faturamento de cada classe mostra um alto grau de atratividade aos produtores e de penetração desse segmento no mercado farmacêutico ético. Deve-se notar que os resultados de faturamento apresentados se referem apenas ao canal de vendas de drogarias e farmácias, excluindo as compras do governo e de hospitais.

Para essa amostra de 88 classes terapêuticas, considerando apenas os medicamentos éticos, quando se reclassifica por princípio ativo, verifica-se que existem 229 princípios ativos que enfrentam a concorrência de medicamentos genéricos. Nesse grupo, a mediana do número de laboratórios produtores de genéricos é igual a 5, enquanto a média corresponde a 6,14 laboratórios. Esse grande número de produtores reflete, em parte, o fato de que, a partir da lei de

(24) Classificação química anatômica terapêutica (Anatomical Therapeutic Chemical - ATC) da Organização Mundial de Saúde (WHO - World Health Organization). 
genéricos, potencialmente, qualquer medicamento de marca produzido no país até 1997, ano em que o TRIPS passou a valer, seria passível de se tornar um medicamento referência de genérico.

A grande quantidade de produtores de medicamentos genéricos reflete, em parte, o fato de existir flexibilidade de oferta na produção do setor farmacêutico, pois vários deles só os fabricam em alguns períodos de boas oportunidades de ganhos, tendo, portanto, o registro na Anvisa para o medicamento em questão. Mas, quando não produzem aquele medicamento especificamente, estão produzindo outros, sem deixar sua atividade no setor farmacêutico.

$\mathrm{O}$ grande número de produtores e o crescimento da participação dos mesmos no mercado de medicamentos genéricos também colocam a questão sobre a capacidade do governo, em sua política regulatória de genéricos, de usar a comunicação oficial para divulgar a boa qualidade do genérico a fim de romper a barreira da falta de credibilidade dos agentes do mercado, especialmente a classe médica e os pacientes. A comunicação oficial foi utilizada como um instrumento para alavancar a concorrência contra as barreiras jurídicas e comerciais ao ingresso de genéricos. O problema associado é que a credibilidade da comunicação oficial ao longo do tempo decorre da credibilidade do próprio governo em não gerar choques não esperados de regulação.

Isso porque, no mercado farmacêutico, a patente vale muito, mas toda a propaganda sobre o produto também possui grande valor. A propaganda no setor farmacêutico é dirigida a toda a cadeia: paciente, médico e varejo (balconista) (Lundin, 2000). Assume formatos diferentes: congressos e amostras grátis para médicos, bônus para balconistas e propaganda indireta para usuários. Estima-se que os diversos tipos de gasto com propaganda e marketing correspondam de $25 \%$ a $30 \%$ do preço do medicamento de marca nos mercados dos países desenvolvedores (Caves et al.,1991). No caso dos países em desenvolvimento, os medicamentos pioneiros chegam com certa defasagem, e a propaganda do país de origem mais o efeito da experiência dos consumidores operam antes do lançamento e tendem a reduzir os custos de divulgação. Desse modo, a propaganda institucional do governo brasileiro parece ter sido capaz de sobrepor os efeitos dos gastos com propaganda dos medicamentos de marca, rompendo barreiras à entrada, erigidas tanto pela via jurídica (patente) quanto pela via comercial (conhecimento e confiança na marca). $\mathrm{O}$ custo de propaganda e marketing para posicionar o produto na frente comercial seria proibitivo para as empresas de genéricos.

Para uma melhor avaliação desses efeitos, verificamos, para 16 classes terapêuticas com informações disponíveis sobre indicações médicas de 
medicamentos da pesquisa do Inte ${ }^{25}$, do IMS, que possuem medicamentos com marcas bastante conhecidas, a evolução das receitas médicas que não indicam alguma marca específica. Verifica-se, na Tabela 6, em anexo, que a participação das indicações médicas sem especificar marcas ou laboratórios aumentou entre 2004 e 2008 , passando de $22,3 \%$ para $31 \%$, sugerindo que as barreiras de marcas vêm sendo arrefecidas, embora se deva notar que esse crescimento pode representar um aumento de atendimentos médicos pelo SUS, onde os médicos são recomendados a indicar somente o princípio ativo.

As estatísticas apresentadas nesta seção, ainda que preliminares e gerais, representam evidências favoráveis à argumentação proposta de que teria ocorrido um aumento da concorrência entre os medicamentos substitutos em relação aos pioneiros de marca negociados em farmácias e drogarias, especificamente entre genéricos e similares, decorrentes das políticas regulatórias de incentivos à concorrência e da formatação do processo produtivo brasileiro.

\section{Conclusões e considerações finais}

O estudo buscou evidenciar que o segmento de medicamentos éticos da indústria farmacêutica brasileira restrito aos bens comercializados em farmácias e drogarias, regulado por preço-teto e sob influência de políticas de incentivos à promoção da concorrência de medicamentos genéricos e de similares, aumentou seu grau de competição como resultado de tais políticas de incentivo à concorrência.

Esse resultado, no entanto, parece decorrer da conjunção de três fatores específicos.

O primeiro é a formatação do processo produtivo farmacêutico brasileiro que, de maneira predominante e esquemática, se constitui na composição/mistura do princípio ativo importado com o material inerte para a composição da forma farmacêutica e sua embalagem em linhas de produção flexíveis por bateladas. É importante notar que, apesar da existência de empresas verticalizadas, a ausência da fase de pesquisa e desenvolvimento de novos princípios ativos (indústria química e bioquímica) em larga escala para a produção de medicamentos pioneiros de marca, e mesmo para medicamentos com a patente expirada, confere incentivos para a importação das moléculas ativas.

O segundo fator consiste na grande disponibilidade de princípios ativos com patentes expiradas para a importação, atualmente garantida por países como a Índia e a China. Além disso, a importação direta (empresa a empresa) das matrizes produtoras, de países como Estados Unidos, Alemanha e França, para suas

(25) Índice Nacional de Terapêutica e Enfermidades - consiste em uma base de dados que classifica as doenças conforme a CID-10 em mercados relevantes definidos. 
empresas subsidiárias no Brasil facilita a entrada de princípios ativos ainda com e sem proteção patentária.

Por fim, a credibilidade dos medicamentos genéricos e similares propiciada pelo agente regulador, considerada o terceiro fator, pareceu ter reduzido as barreiras à entrada de novos produtores nos mercados de medicamentos éticos investigados neste estudo.

Tais medicamentos, que impõem concorrência aos medicamentos de marca com patente expirada, passaram a ser produzidos predominantemente por meio da importação dos seus princípios ativos e tiveram suas demandas garantidas pela credibilidade de testes de bioequivalência avalizados pelo agente regulador. A predominância de apenas uma parte do processo vertical da indústria farmacêutica no país, caracterizada pelo processo de produção multiproduto da indústria farmacêutica por bateladas, permite a flexibilidade de oferta em arbitragens de preços no mercado farmacêutico. Assim, dadas as características do processo produtivo no País, as possibilidades conjunturais de importação do princípio ativo e o aparato regulatório, os dados sugerem diminuição das barreiras à entrada de novas firmas produtoras de medicamentos com patentes expiradas.

A política de medicamentos genéricos implantada a partir de 1999 parece ter sido eficaz para a promoção do uso desses medicamentos no País. O crescente aumento da sua participação no faturamento das classes terapêuticas em que atua ao longo da década de 2010 sugere esse fato, em especial, por ter sido capaz de sinalizar a qualidade do medicamento genérico por meio de canais de propaganda do governo, apesar dos efeitos da propaganda e da experiência dos medicamentos pioneiros de marca sobre os consumidores.

Esses resultados preliminares, entretanto, precisam ainda ser avaliados por técnicas mais adequadas no que se refere estritamente à mensuração de bem-estar. Além disso, deve-se considerar que o efeito da regulação por preço-teto, que impede a flexibilidade dos preços dos medicamentos para cima, deve causar ruídos no esquema de incentivos. Estudos como o de Chaudhuri et al. (2006) apresentam evidências de efeitos negativos sobre o bem-estar decorrentes da adequação dos direitos de propriedade acordados no TRIPS, na Índia. Nesse estudo, a partir do pressuposto do reconhecimento dos direitos de propriedade no setor, foi avaliada a variação do excedente dos consumidores de quinolones, e se verificou sua redução para o caso dessa classe de medicamentos, supostamente representativa do mercado farmacêutico indiano. Para o Brasil, cujas atividades regulatórias mais expressivas ocorreram logo após a adesão ao TRIPS, avaliar tais atividades se relaciona intrinsecamente com avaliar os efeitos da adesão de propriedade sobre o excedente total ou do consumidor num prazo mais largo. O maior impedimento para um estudo semelhante ao indiano, no caso brasileiro, consiste, portanto, na dificuldade de obtenção de dados desagregados sobre o setor. 
Marislei Nishijima / Geraldo Biasoto Jr./ Eleni Lagroteria

\section{Referências bibliográficas}

ALEXANDER, I.; IRWIN, T. Price caps, rate-of-return regulation, and the cost of capital. Public policy for the private sector. 1996. (World Bank, note n. 87).

CAVES, R. E.; Whisthon, M. D.; HURWITZ, M. A. Patent expiration, entry, and competition in the U.S. pharmaceutical industry. Brookings Papers, Microeconomics, 1991.

CHAUDHURI, S; GOLDBERG, P. K.; JIA, P. Estimating the effects of global patent protection in pharmaceuticals: a case study of Quinolones in India. The American Economic Review, v. 96, n. 5 p. 1477-1514, Dec. 2006.

GRABOWSKI, H.; VERNON, J. Brand Loyalty, entry and price competition in pharmaceutical after the 1984 "Drug Act". The Journal of Law and Economics, v. XXXV, Oct. 1992.

HURWITZ, M. A.; CAVES, R. E. Persuasion or information? Promotion and the shares of brand name and generic pharmaceuticals. The Journal of Law and Economics, v. XXXI, Oct. 1988.

KAMIEN, M. K.; ZANH, I. Virtual patent extension by cannibalization. Southern Economic Journal, v. 66, n. 1, p. 117-131, 1999.

LAFONT, J.J.; TIROLE, J. A theory of incentives in procurement and regulation. Cambridge: The MIT Press, 1993.

LISBOA, M. In: SALGADO, L. H.; MOTTA R. S. (Ed.). Regulação e concorrência no Brasil: governança, incentivos e eficiência. Ipea, 2007.

LUNDIN, D. Moral hazard in physician prescription behavior. Journal of Health Economics, v. 19, p. 639-662, 2000.

MAGAlHÃES, J. L.; ANTUNES, A. M. S.; BOECHAT, N. Laboratórios farmacêuticos oficiais e sua relevância para saúde pública do Brasil. RECIIS - R. Eletr. de Com. Inf. Inov. Saúde, Rio de Janeiro, v. 5, n. 1, mar. 2011. Disponível em: http://www.reciis.cict.fiocruz.br/index.php/reciis/article/viewArticle/367/760

MATOS, J. L. Implementação de um projeto de melhorias em um processo de reação química em batelada utilizando o método DMAIC. Dissertação (Mestrado)-Universidade Federal do Rio Grande do Sul, Porto Alegre, 2003.

MILGROM, P.; ROBERTS, J. Economics, organization and management. New Jersey: Prentice Hall, 1992.

NISHIJIMA, M. Análise econômica dos medicamentos genéricos no Brasil. Tese (Doutorado)-Instituto de Pesquisas Econômicas da Universidade de São Paulo (IPE/USP), 2003.

ROCHA, F.; SOUZA, I. V. Reajuste de preços na indústria farmacêutica brasileira e o fator $\mathrm{X}$ : uma avaliação usando o método de fronteiras estocásticas. In: ENCONTRO NACIONAL DE ECONOMIA, 35, Recife, 2007. 
SALGADO, L. H.; MOTTA R. S. (Ed.). Regulação e concorrência no Brasil: governança, incentivos e eficiência. Ipea, 2007.

VISCUSI, W. K.; HARRINGTON Jr., J. E.; VERNON, J. M. Economics of regulation and antitrust. 4. ed. United States of America: MIT Press, 2005. 
Marislei Nishiijima / Geraldo Biasoto Jr./ Eleni Lagroteria

Anexo

Tabela 1

Investimentos médios estimados para OBTENÇÃO de registro de medicamento genérico junto à Anvisa - valores de 2009

\begin{tabular}{lc}
\hline \multicolumn{1}{c}{ Tipo de Custo } & Valor \\
\hline $\begin{array}{l}\text { Custo de desenvolvimento (estabilidade, } \\
\text { desenvolvimento, metodologia analítica etc.) }\end{array}$ & $\mathrm{RS} 200.000$ \\
Estudo de equivalência farmacêutica, & $\mathrm{R} \$ 15.000^{* *}$ \\
incluindo perfil de dissolução & \\
Estudo de bioequivalência & $\mathrm{R} \$ 300.000^{* *}$ \\
Submissão Anvisa por forma farmacêutica & $\mathrm{R} \$ 6.000$ \\
Elaboração de relatório & $\mathrm{R} \$ 5.000$ \\
Manutenção do registro & $\mathrm{R} \$ 5.400$ \\
Total & $\mathrm{R} \$ 531.400$ \\
\hline
\end{tabular}

* Exclusive PAs; ** Exemplo de 1 produto com 1 ativo em 1 forma farmacêutica. Fonte: Parecer SEAE (Parecer n. 06568/2009 COGCE/SEAE/MN).

Tabela 2

Investimentos médios estimados para obtenção de registro de medicamento similar junto a Anvisa - valores de 2009

\begin{tabular}{lc}
\hline \multicolumn{2}{c}{ Registro de medicamento Similar } \\
\hline $\begin{array}{l}\text { Custo de desenvolvimento (estabilidade, } \\
\text { desenvolvimento, metodologia analítica etc.)* }\end{array}$ & $\mathrm{RS} 200.000$ \\
$\begin{array}{l}\text { Estudo de equivalência farmacêutica, incluindo } \\
\text { perfil de dissolução }\end{array}$ & $\mathrm{R} \$ 15.000^{* *}$ \\
Estudo de bioequivalência & $\mathrm{R} \$ 300.000^{* *}$ \\
Submissão Anvisa & $\mathrm{R} \$ 21.000$ \\
Elaboração de relatório & $\mathrm{R} \$ 5.000$ \\
Manutenção do registro & $\mathrm{R} \$ 18.900$ \\
Total & $\mathrm{R} \$ 559.900$ \\
\hline
\end{tabular}

* Exclusive PAs; **1 produto com 1 ativo em 1 forma farmacêutica.

Fonte: Parecer SEAE. 
A competição no mercado farmacêutico brasileiro após uma década de medicamentos genéricos

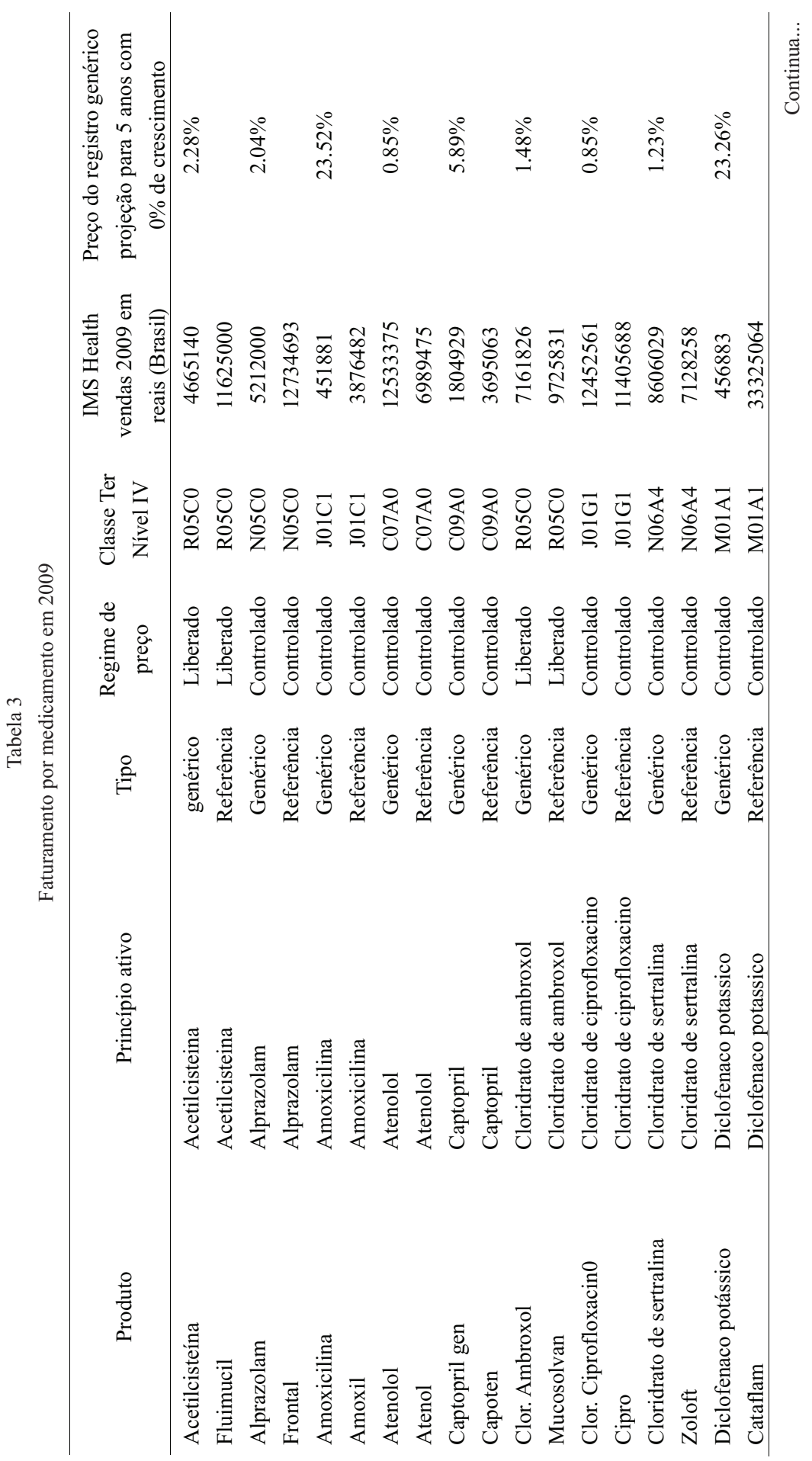

Economia e Sociedade, Campinas, v. 23, n. 1 (50), p. 155-186, abr. 2014. 
Marislei Nishijima / Geraldo Biasoto Jr./ Eleni Lagroteria

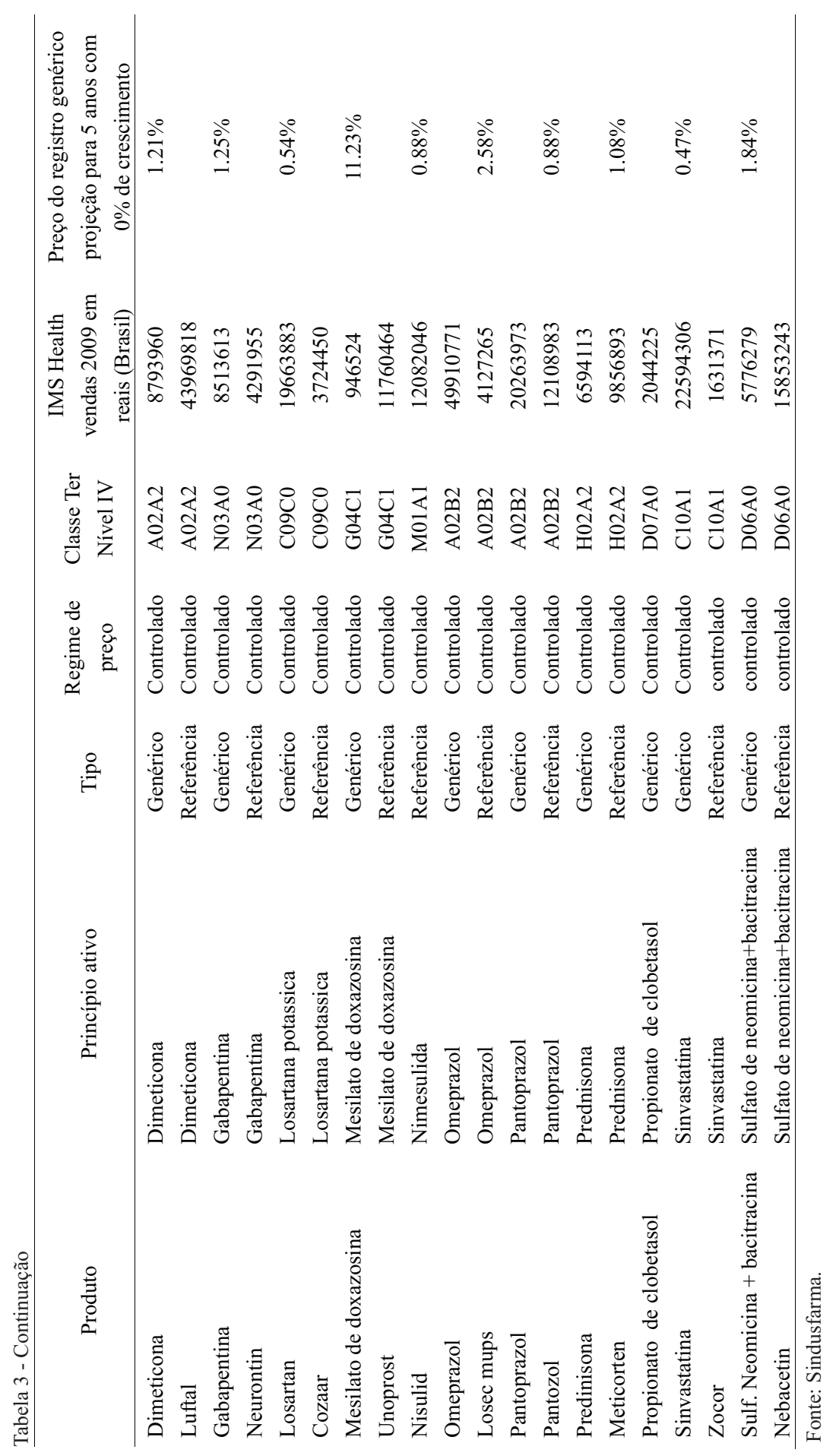




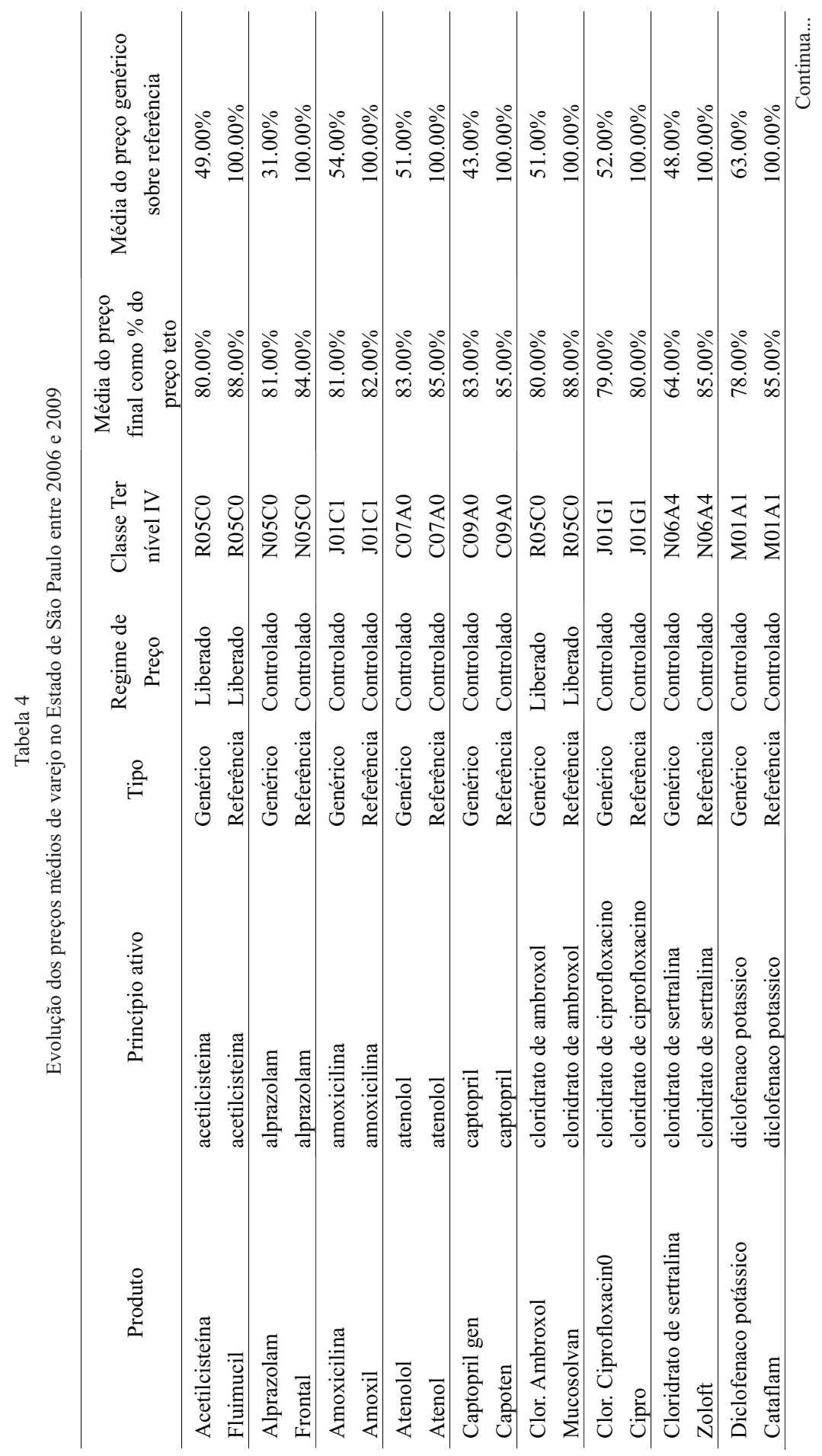

Economia e Sociedade, Campinas, v. 23, n. 1 (50), p. 155-186, abr. 2014. 
Marislei Nishijima / Geraldo Biasoto Jr./ Eleni Lagroteria

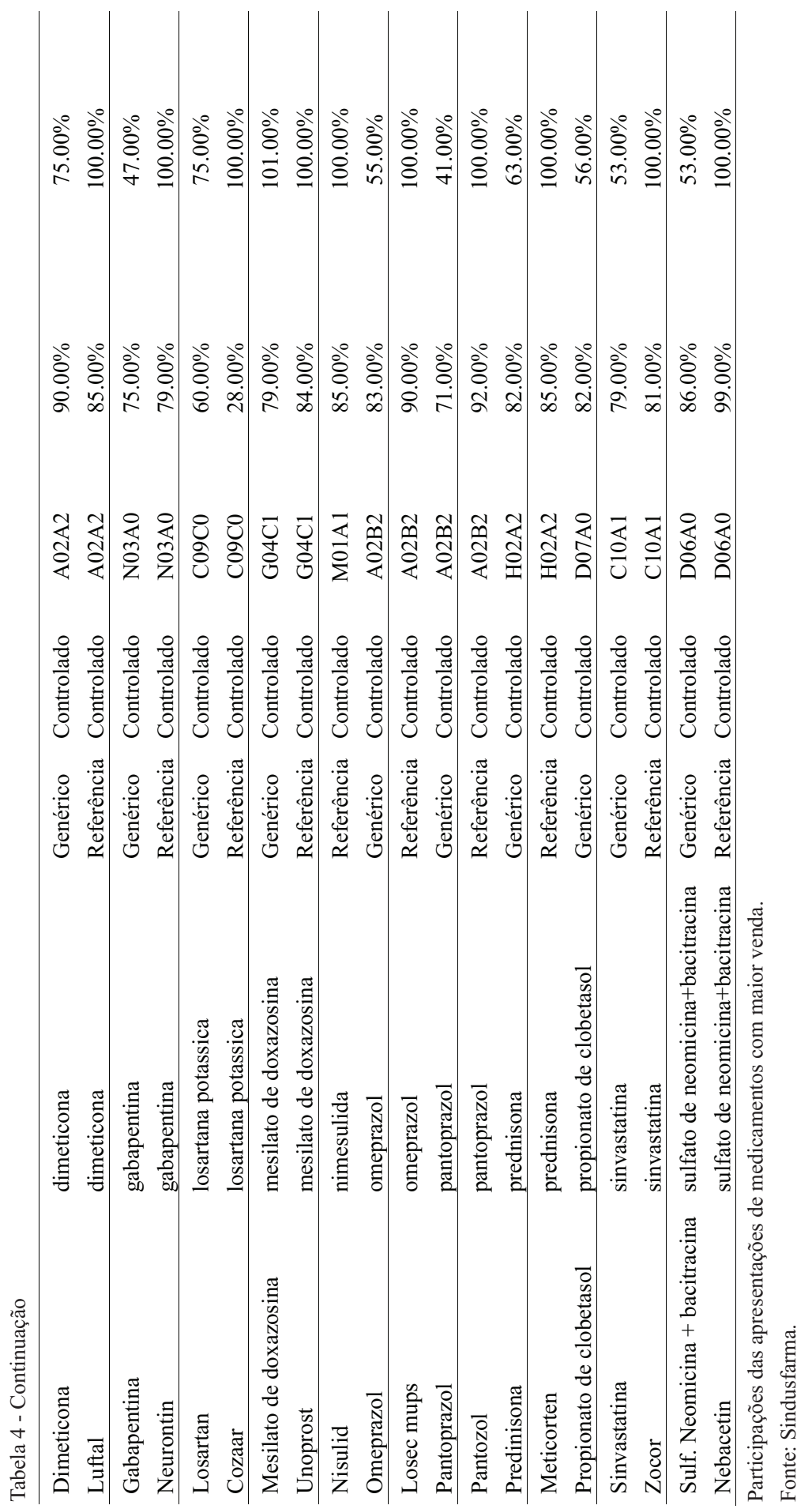


Tabela 5

Evolução da participação no faturamento dos medicamentos genéricos

\begin{tabular}{|c|c|c|c|c|c|}
\hline $\begin{array}{c}\text { Classe Terapêutica } \\
\text { N4 }\end{array}$ & 2002 & 2004 & 2006 & 2008 & 2009 \\
\hline A03D0 & $0.10 \%$ & $0.00 \%$ & $0.00 \%$ & $0.10 \%$ & $0.50 \%$ \\
\hline A03E0 & $0.00 \%$ & $0.50 \%$ & $15.40 \%$ & $36.00 \%$ & $60.40 \%$ \\
\hline A03F0 & $1.40 \%$ & $5.40 \%$ & $10.60 \%$ & $15.20 \%$ & $19.40 \%$ \\
\hline A08A0 & $0.00 \%$ & $0.00 \%$ & $28.90 \%$ & $40.80 \%$ & $41.00 \%$ \\
\hline $\mathrm{A} 10 \mathrm{H} 0$ & $2.60 \%$ & $9.50 \%$ & $23.70 \%$ & $33.80 \%$ & $35.90 \%$ \\
\hline A10J1 & $34.40 \%$ & $56.50 \%$ & $66.10 \%$ & $62.20 \%$ & $56.70 \%$ \\
\hline B01C2 & $12.90 \%$ & $11.40 \%$ & $7.50 \%$ & $54.20 \%$ & $63.70 \%$ \\
\hline C01B0 & $7.60 \%$ & $12.90 \%$ & $10.20 \%$ & $13.00 \%$ & $17.00 \%$ \\
\hline $\mathrm{C} 03 \mathrm{~A} 2$ & $7.80 \%$ & $14.00 \%$ & $8.50 \%$ & $15.80 \%$ & $25.60 \%$ \\
\hline $\mathrm{C} 03 \mathrm{~A} 2$ & $6.60 \%$ & $12.00 \%$ & $6.70 \%$ & $10.30 \%$ & $19.10 \%$ \\
\hline C04A1 & $12.70 \%$ & $18.60 \%$ & $16.70 \%$ & $13.40 \%$ & $11.00 \%$ \\
\hline $\mathrm{C} 04 \mathrm{~A} 2$ & $0.60 \%$ & $1.50 \%$ & $4.20 \%$ & $9.50 \%$ & $10.90 \%$ \\
\hline C07A0 & $21.40 \%$ & $30.90 \%$ & $39.10 \%$ & $46.20 \%$ & $48.30 \%$ \\
\hline $\mathrm{C} 07 \mathrm{~B} 1$ & $0.00 \%$ & $5.20 \%$ & $12.60 \%$ & $17.00 \%$ & $18.10 \%$ \\
\hline C09A0 & $31.20 \%$ & $36.60 \%$ & $45.30 \%$ & $56.10 \%$ & $56.40 \%$ \\
\hline C09B1 & $1.70 \%$ & $6.70 \%$ & $11.60 \%$ & $14.70 \%$ & $13.70 \%$ \\
\hline $\mathrm{C} 09 \mathrm{C} 0$ & $0.10 \%$ & $5.80 \%$ & $11.10 \%$ & $17.70 \%$ & $21.90 \%$ \\
\hline C09D1 & $0.00 \%$ & $0.00 \%$ & $2.10 \%$ & $5.80 \%$ & $8.10 \%$ \\
\hline C10A1 & $23.60 \%$ & $30.70 \%$ & $25.50 \%$ & $22.40 \%$ & $19.10 \%$ \\
\hline $\mathrm{C} 10 \mathrm{~A} 2$ & $7.10 \%$ & $8.00 \%$ & $11.60 \%$ & $14.10 \%$ & $18.70 \%$ \\
\hline D01A1 & $11.50 \%$ & $15.60 \%$ & $23.50 \%$ & $25.90 \%$ & $27.00 \%$ \\
\hline D06A0 & $2.60 \%$ & $7.50 \%$ & $16.10 \%$ & $23.70 \%$ & $26.40 \%$ \\
\hline D07A0 & $3.30 \%$ & $7.80 \%$ & $16.80 \%$ & $24.20 \%$ & $26.30 \%$ \\
\hline D07B1 & $0.50 \%$ & $4.40 \%$ & $11.70 \%$ & $16.80 \%$ & $18.70 \%$ \\
\hline D07B3 & $1.50 \%$ & $15.40 \%$ & $27.60 \%$ & $29.10 \%$ & $30.60 \%$ \\
\hline G01A1 & $5.50 \%$ & $19.10 \%$ & $32.90 \%$ & $39.00 \%$ & $38.60 \%$ \\
\hline G01A2 & $3.40 \%$ & $12.00 \%$ & $21.00 \%$ & $27.80 \%$ & $30.80 \%$ \\
\hline G01B0 & $6.20 \%$ & $13.00 \%$ & $20.70 \%$ & $24.70 \%$ & $25.80 \%$ \\
\hline G03A1 & $0.00 \%$ & $0.00 \%$ & $0.00 \%$ & $0.50 \%$ & $0.60 \%$ \\
\hline G04C1 & $8.50 \%$ & $13.20 \%$ & $19.70 \%$ & $26.80 \%$ & $27.90 \%$ \\
\hline $\mathrm{H} 02 \mathrm{~A} 2$ & $1.80 \%$ & $7.50 \%$ & $16.00 \%$ & $22.60 \%$ & $26.20 \%$ \\
\hline Н02B0 & $1.60 \%$ & $5.10 \%$ & $13.40 \%$ & $17.40 \%$ & $17.60 \%$ \\
\hline J01 A0 & $6.20 \%$ & $10.00 \%$ & $10.20 \%$ & $17.40 \%$ & $21.00 \%$ \\
\hline $\mathrm{J} 01 \mathrm{C} 1$ & $56.10 \%$ & $58.80 \%$ & $59.30 \%$ & $57.00 \%$ & $57.40 \%$ \\
\hline J01D1 & $51.40 \%$ & $69.10 \%$ & $78.10 \%$ & $78.60 \%$ & $79.20 \%$ \\
\hline J01F0 & $12.30 \%$ & $19.40 \%$ & $23.50 \%$ & $30.80 \%$ & $35.10 \%$ \\
\hline J01G1 & $15.80 \%$ & $24.40 \%$ & $30.50 \%$ & $39.30 \%$ & $41.90 \%$ \\
\hline $\mathrm{J} 02 \mathrm{~A} 0$ & $20.10 \%$ & $36.10 \%$ & $49.00 \%$ & $48.30 \%$ & $45.50 \%$ \\
\hline M01A1 & $10.70 \%$ & $19.20 \%$ & $27.70 \%$ & $30.60 \%$ & $30.80 \%$ \\
\hline M02A0 & $0.00 \%$ & $2.00 \%$ & $0.10 \%$ & $0.00 \%$ & $0.00 \%$ \\
\hline
\end{tabular}

Continua... 
Marislei Nishijima / Geraldo Biasoto Jr./ Eleni Lagroteria

\begin{tabular}{|c|c|c|c|c|c|}
\hline $\begin{array}{c}\text { Classe Terapêutica } \\
\text { N4 }\end{array}$ & 2002 & 2004 & 2006 & 2008 & 2009 \\
\hline М03B0 & $0.20 \%$ & $0.00 \%$ & $1.10 \%$ & $5.00 \%$ & $6.60 \%$ \\
\hline N02B0 & $0.50 \%$ & $0.90 \%$ & $6.70 \%$ & $12.80 \%$ & $15.20 \%$ \\
\hline N02B0 & $0.40 \%$ & $0.90 \%$ & $5.00 \%$ & $9.40 \%$ & $10.70 \%$ \\
\hline N03A0 & $5.20 \%$ & $10.00 \%$ & $9.30 \%$ & $14.60 \%$ & $17.30 \%$ \\
\hline N03A0 & $3.80 \%$ & $7.40 \%$ & $8.80 \%$ & $14.80 \%$ & $16.10 \%$ \\
\hline N05A9 & $0.00 \%$ & $0.00 \%$ & $0.20 \%$ & $0.20 \%$ & $0.10 \%$ \\
\hline $\mathrm{N} 05 \mathrm{C} 0$ & $5.60 \%$ & $14.00 \%$ & $25.20 \%$ & $38.10 \%$ & $43.70 \%$ \\
\hline $\mathrm{N} 05 \mathrm{C} 0$ & $3.30 \%$ & $9.00 \%$ & $16.90 \%$ & $28.40 \%$ & $33.80 \%$ \\
\hline N06A4 & $16.70 \%$ & $17.00 \%$ & $19.90 \%$ & $30.70 \%$ & $34.80 \%$ \\
\hline N06A5 & $0.00 \%$ & $0.00 \%$ & $11.90 \%$ & $23.00 \%$ & $22.80 \%$ \\
\hline N06A9 & $0.30 \%$ & $8.60 \%$ & $19.40 \%$ & $26.80 \%$ & $28.20 \%$ \\
\hline N06D0 & $1.20 \%$ & $1.90 \%$ & $0.00 \%$ & $0.00 \%$ & $0.00 \%$ \\
\hline $\mathrm{P} 01 \mathrm{~A} 0$ & $4.00 \%$ & $6.90 \%$ & $17.80 \%$ & $11.70 \%$ & $12.40 \%$ \\
\hline $\mathrm{P} 01 \mathrm{~B} 0$ & $13.80 \%$ & $19.50 \%$ & $21.90 \%$ & $21.10 \%$ & $23.80 \%$ \\
\hline R01A7 & $0.00 \%$ & $1.50 \%$ & $2.30 \%$ & $4.40 \%$ & $6.20 \%$ \\
\hline R01B0 & $0.00 \%$ & $2.30 \%$ & $8.50 \%$ & $6.50 \%$ & $6.60 \%$ \\
\hline $\mathrm{R} 03 \mathrm{C} 2$ & $22.20 \%$ & $41.00 \%$ & $45.90 \%$ & $50.30 \%$ & $44.90 \%$ \\
\hline $\mathrm{R} 05 \mathrm{C} 0$ & $3.40 \%$ & $10.60 \%$ & $16.20 \%$ & $18.20 \%$ & $18.80 \%$ \\
\hline R05D1 & $2.30 \%$ & $7.60 \%$ & $15.30 \%$ & $13.80 \%$ & $14.00 \%$ \\
\hline R05D2 & $0.00 \%$ & $1.10 \%$ & $7.00 \%$ & $6.30 \%$ & $8.00 \%$ \\
\hline R06A0 & $2.50 \%$ & $9.80 \%$ & $12.90 \%$ & $12.40 \%$ & $13.60 \%$ \\
\hline R06A0 & $1.80 \%$ & $7.80 \%$ & $10.30 \%$ & $9.60 \%$ & $10.10 \%$ \\
\hline
\end{tabular}

Fonte: IMS

Tabela 6

Evolução média das indicações de medicamentos em receitas médicas

\begin{tabular}{cccccc}
\hline Indicação de Laboratório & 2004 & 2005 & 2006 & 2007 & 2008 \\
\hline Não Indicado & $22.30 \%$ & $22.90 \%$ & $25.80 \%$ & $30.00 \%$ & $31.00 \%$ \\
\hline
\end{tabular}

Fonte: Pesquisa INTE do IMS. 